\title{
Red and processed meat consumption and risk of ovarian cancer: a dose-response meta-analysis of prospective studies
}

\author{
A Wallin', N Orsini' and A Wolk*,I \\ 'Division of Nutritional Epidemiology, Institute of Environmental Medicine, Karolinska Institute, Box 210, Stockholm 171 77, Sweden
}

BACKGROUND: During the last decade, the epidemiological evidence on consumption of meat and risk of ovarian cancer has accumulated.

METHODS: We assessed the relationship between red and processed meat consumption and risk of ovarian cancer with a doseresponse meta-analysis. Relevant prospective cohort studies were identified by searching the PubMed and EMBASE databases through $2 \mathrm{I}$ January 20 II, and by reviewing the reference lists of retrieved articles. Study-specific relative risk (RR) estimates were combined using a random-effects model.

RESULTS: Eight cohort studies were included in the meta-analysis. The summary RR for an intake increment of $100 \mathrm{~g}$ per week was 1.02 (95\% confidence interval (Cl), 0.99-1.04) for red meat and 1.05 (95\% Cl, $0.98-1.14$ ) for processed meat. For an intake increment of four servings per week, the summary RR of ovarian cancer was $1.07(95 \% \mathrm{Cl}, 0.97-\mathrm{I} .19)$ for red meat (I00 g per serving) and 1.07 (95\% Cl, $0.97-1.17)$ for processed meat (30 g per serving).

CONCLUSION: Results from this dose-response meta-analysis suggest that red and processed meat consumption is not associated with risk of ovarian cancer. Although a lower consumption of red and processed meat may offer protection against other types of cancer, other interventions are needed to reduce the risk of ovarian cancer.

British Journal of Cancer (201 I) 1 04, I196-1201. doi:10.1038/bjc.201 I.49 www.bjcancer.com

Published online 22 February 2011

(C) 201। Cancer Research UK

Keywords: cohort studies; meat; meta-analysis; ovarian cancer; prospective studies; systematic review

Although ovarian cancer is less common among women than cancer of the breast and uterus, it has a higher case-fatality rate (Parkin et al, 2005; Ferlay et al, 2010). The poor prognosis is largely due to late diagnosis. Although most women with localised ovarian cancer are cured, $70-75 \%$ of cases are diagnosed with advanced-stage disease, with a 5-year survival of about $20-30 \%$ (Parkin and Iscovich, 1997). Many of the factors most consistently associated with ovarian cancer risk are not easily modified. The best recognised protective factors include oral contraceptive use and parity, while infertility, early age at menarche, late age at menopause and talc use have been associated with an increased risk (Sueblinvong and Carney, 2009). Thus, identification of modifiable life-style factors, including diet, could provide an opportunity for primary prevention.

In a recent meta-analysis of seven case-control and four cohort studies (Kolahdooz et al, 2010), the evidence on meat consumption in relation to ovarian cancer risk was summarised. However, in this meta-analysis based on risk estimates for the highest $v s$ the lowest category of consumption, the interpretation of the summary relative risk (RR) can be problematic. Results from the individual studies are largely dependent on the range of exposure, which can vary considerably between studies conducted in different populations. For example, while $\leqslant 3$ servings per week was the lowest category in one of the studies included in the red meat analysis (Tavani et al, 2000), $\geqslant 2$ servings per week was the highest category of consumption in another study (Bertone et al, 2002).

*Correspondence: Dr A Wolk; E-mail: Alicja.Wolk@ki.se

Received 8 November 2010; revised 21 January 2011; accepted 27 January 201 I; published online 22 February 2011
Consequently, the summary RR based on categorical comparison becomes a vague instrument to illustrate the magnitude and implications of an association.

In most of the analyses by Kolahdooz et al (2010), there was statistically significant heterogeneity when risk estimates from all studies were pooled, suggesting that it is inappropriate to draw conclusions from these results. As revealed by the stratification by study type, much of the heterogeneity was attributable to the inclusion of studies with different designs. Compared with casecontrol studies, prospective cohort studies provide a higher level of evidence because of lower susceptibility to recall and selection bias, and the pooled estimates from these studies should be valued higher.

A dose-response meta-analysis limited to prospective cohort studies offers a solution to the problems presented, and would be a valuable complement to the previous meta-analysis. From a public health perspective, dose-response meta-analyses can provide more useful estimates better quantifying associations between specified amounts of food and disease risk. Therefore, to clarify a potential association between red and processed meat and ovarian cancer risk, we performed a dose-response meta-analysis limited to prospective cohort studies only.

\section{MATERIALS AND METHODS}

\section{Search strategy}

Eligible studies were identified by searching the PubMed and EMBASE databases through 21 January 2011. The keywords ovarian cancer or ovary and cancer were used in combination 
with meat, red meat, processed meat, pork, beef or foods. Further, the reference lists of retrieved articles and relevant review articles were examined for additional relevant studies. No language restrictions were imposed. This systematic review was planned, conducted and reported in adherence to standards of quality for reporting meta-analysis (MOOSE) (Stroup et al, 2000).

\section{Eligibility criteria}

Studies were included in the meta-analysis if they met the following criteria: (1) prospective cohort design; (2) the exposure studied was red meat or processed meat; (3) the outcome of interest was incidence of or mortality from epithelial ovarian cancer; and (4) RR with corresponding 95\% confidence intervals (CIs) (or data to calculate these) were presented.

\section{Data extraction}

Data extracted from each study included the first author's last name, publication year, country where the study was performed, study period, number of cases and cohort size, measure and range of exposure, variables adjusted for in the analysis, and RRs with corresponding $95 \%$ CIs for each category of consumption of red meat and/or processed meat. When several risk estimates were presented for each type of meat, the ones adjusted for the greatest number of potential confounders were used. The study quality was assessed using the Newcastle - Ottawa Quality Assessment Scale for cohort studies, with which each study is judged based on the selection of the study groups, the comparability of the groups, and the ascertainment of exposure and outcome (Wells et al, 2011). Data extraction was conducted independently by two authors (Wallin and Orsini), with disagreements resolved by consensus.

\section{Statistical analysis}

We used the method proposed by Greenland and Longnecker (1992) and Orsini et al (2006) to compute the trend from the correlated log RR estimates across categories of consumption. We investigated a potential non-linear relationship using restricted cubic splines, but found no evidence of non-linearity. As the included studies used different units to report consumption (i.e., grams or servings), we rescaled consumption into servings per week. We used $100 \mathrm{~g}$ as the approximate average serving size for red meat, and $30 \mathrm{~g}$ for processed meat. The median level of consumption for each category was assigned to each corresponding RR estimate. When the median consumption per category was not presented in the article, the midpoint between the upper and lower boundary was used. If the lowest category was open-ended, the lower boundary was assumed to be zero. If the upper boundary of the highest category was not provided, we assumed it to be of the same amplitude as the preceding category. In addition, we performed a sensitivity analysis assigning different doses to the top categories (1.2-1.8 times the lower boundary). Statistical heterogeneity between studies was evaluated by using the $Q$ and $I^{2}$ statistics (Higgins and Thompson, 2002). Publication bias was evaluated with the use of a funnel plot and with the Egger regression asymmetry test (Egger et al, 1997). $P<0.05$ was considered statistically significant. All statistical analyses were performed with Stata software, version 10 (Stata Corp., College Station, TX, USA).

\section{RESULTS}

\section{Literature search}

A flowchart of the identification of relevant studies is shown in Figure 1. A total of 1161 articles were identified by searching the databases, 141 duplicated articles in the two databases and 1011

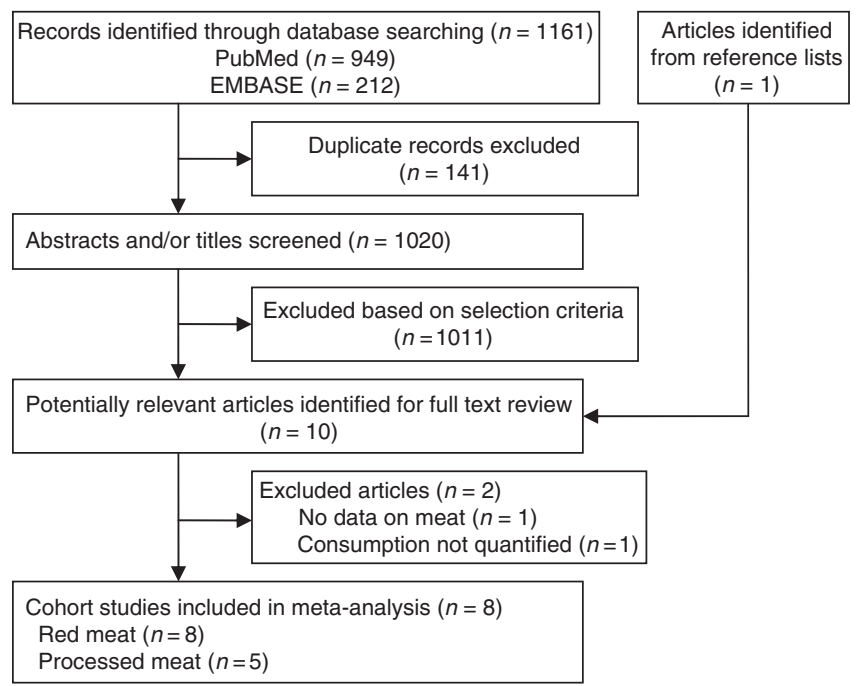

Figure I Flowchart of selection of studies for inclusion in meta-analysis.

articles that did not meet the selection criteria were excluded. The remaining nine articles and one additional article (Cross et al, 2007) identified from reference lists were obtained for full-text review. Among these, one article was excluded because it did not present data on intake of meat in relation to risk of ovarian cancer (Chang et al, 2007), and one was excluded because meat consumption was not quantified (Knekt et al, 1994). The remaining eight prospective cohort studies were included in the meta-analysis (Kushi et al, 1999; Bertone et al, 2002; Larsson and Wolk, 2005; Kiani et al, 2006; Cross et al, 2007; Sakauchi et al, 2007; Schulz et al, 2007; Gilsing et al, 2011). Compared with the previous meta-analysis (Kolahdooz et al, 2010), we additionally included four cohort studies. The Adventist Health Study (Kiani et al, 2006) was included in the red meat analysis, as the reason for exclusion declared by Kolahdooz et al does not apply to a doseresponse approach. We added also one American study that reported RR for unspecified meat (Kushi et al, 1999), assuming that the major part of this meat consumption is red meat. Moreover, one new study reporting on both red and processed meat consumption has been published (Gilsing et al, 2011). In addition, we included one study (Sakauchi et al, 2007) that reported risk estimates for red and processed meat consumption in relation to ovarian cancer mortality.

\section{Study characteristics}

Characteristics of the included studies are presented in Table 1. The eight prospective cohort studies were published between 1999 and 2011 and involved a total of 754836 participants and 2349 epithelial ovarian cancer cases. The outcome was incidence of ovarian cancer in seven studies (Kushi et al, 1999; Bertone et al, 2002; Larsson and Wolk, 2005; Kiani et al, 2006; Cross et al, 2007; Schulz et al, 2007; Gilsing et al, 2011), and mortality from ovarian cancer in one study (Sakauchi et al, 2007). Four studies were conducted in the United States (Kushi et al, 1999; Bertone et al, 2002; Kiani et al, 2006; Cross et al, 2007), 1 in 10 European countries (Schulz et al, 2007) and 1 each in Sweden (Larsson and Wolk, 2005), the Netherlands (Gilsing et al, 2011) and Japan (Sakauchi et al, 2007). Two studies were cohorts of only postmenopausal women (Kushi et al, 1999; Gilsing et al, 2011). The quality rating of the included studies ranged from five to eight stars on the scale of nine, with all but two studies meeting criteria for six stars (Bertone et al, 2002; Larsson and Wolk, 2005). All eight studies provided RR estimates adjusted for age, all but one 


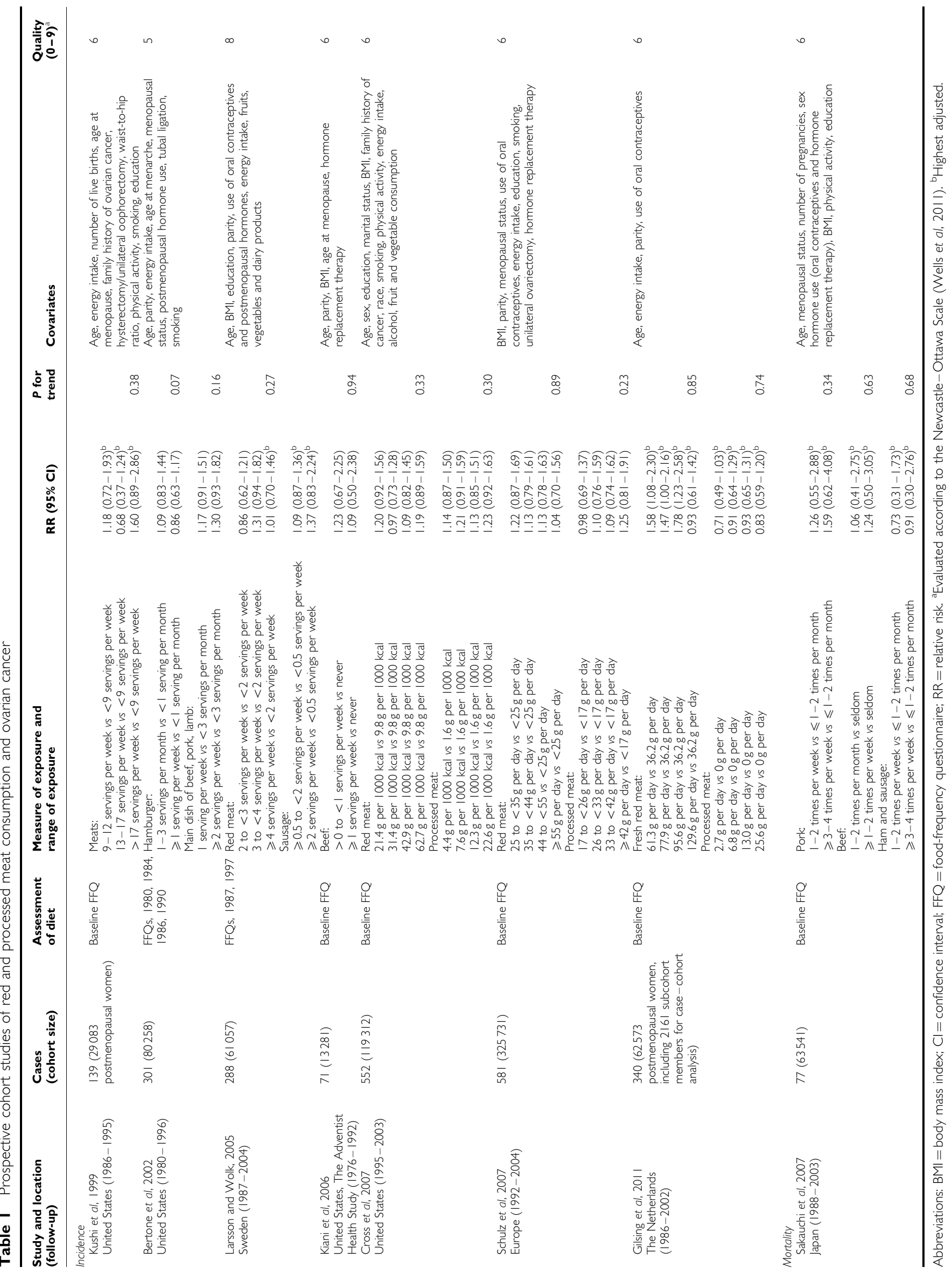


Meat and ovarian cancer for every $100 \mathrm{~g}$ per week increment

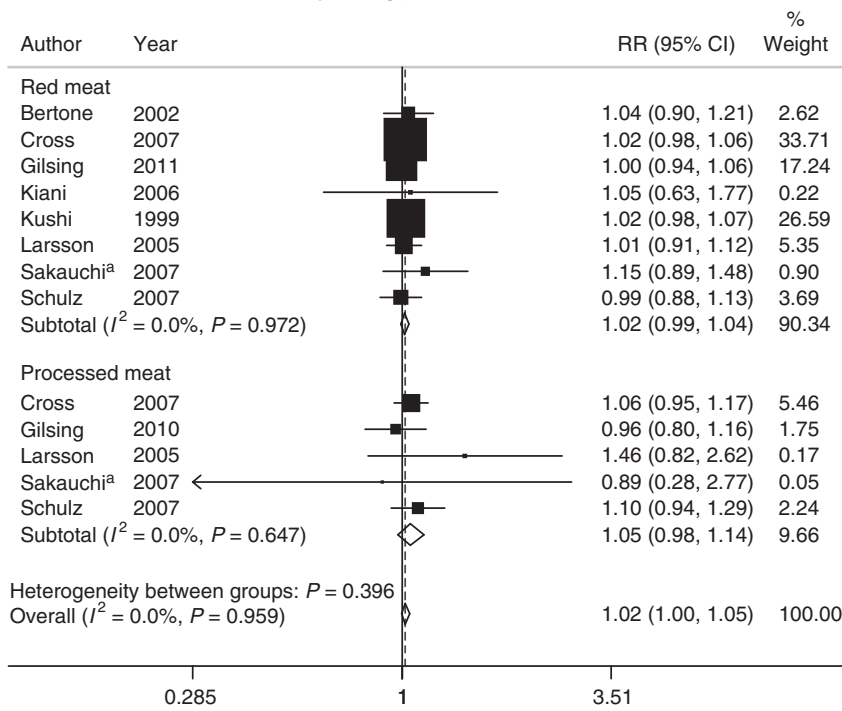

Figure 2 Relative risks of ovarian cancer associated with a $100 \mathrm{~g}$ per week increment in red or processed meat consumption. ${ }^{a}$ Outcome was mortality from ovarian cancer. Excluding this study did not appreciably change the results (RR for red meat, I.02 (95\% Cl, 0.99-1.04); RR for processed meat, I.06 (95\% Cl, $0.98-1.14)$; overall summary RR, I.02 (95\% $\mathrm{Cl}, \mathrm{I} .00-1.05)$ ).

study were further adjusted for parity (Cross et al, 2007), and all but two for body mass index (BMI) or waist-to-hip ratio (Bertone et al, 2002; Gilsing et al, 2011), and for total energy intake (Kiani et al, 2006; Sakauchi et al, 2007). Other covariates were less consistently used. All studies used self-administered foodfrequency questionnaires (FFQ) to assess diet, and two studies updated the information with additional FFQs after baseline (Bertone et al, 2002; Larsson and Wolk, 2005). Two studies presented results for more than one relevant type of red meat (Bertone et al, 2002; Sakauchi et al, 2007). For those, we used the weighted average of the two estimates in the analysis of red meat consumption. The mean range of intake between the highest and the lowest category across studies was about 4.1 servings per week for red meat and about 5.5 servings per week for processed meat.

\section{Dose response of red and processed meat consumption}

The summary RR for an intake increment of $100 \mathrm{~g}$ per week was 1.02 (95\% CI, 0.99-1.04) for red meat and 1.05 (95\% CI, $0.98-$ 1.14) for processed meat. Combining the two types of meat resulted in an overall summary RR of 1.02 (95\% CI, $1.00-1.05$ ) (Figure 2). There was no heterogeneity between studies of red meat $\left(P=0.97 ; I^{2}=0.0 \%\right)$, between studies of processed meat $(P=0.65$; $\left.I^{2}=0.0 \%\right)$, or in the overall summary estimate $(P=0.96$; $\left.I^{2}=0.0 \%\right)$. For an intake increment of four servings per week, the summary RR of ovarian cancer was 1.07 (95\% CI, 0.97-1.19) for red meat ( $100 \mathrm{~g}$ per serving) and 1.07 (95\% CI, $0.97-1.17$ ) for processed meat ( $30 \mathrm{~g}$ per serving). The Egger test showed no evidence of publication bias $(P=0.20)$ (Figure 3$)$.

In sensitivity analyses around the assignment of the dose of the top categories of consumption in studies that did not report median values, the summary estimates were not changed $(R R=1.02$ and $R R=1.05$ for every $100 \mathrm{~g}$ per week increment in consumption of red and processed meat, respectively). Excluding the largest study (Schulz et al, 2007), which accounted for $43 \%$ of the total number of participants and $25 \%$ of cases, did not appreciably change the results $(\mathrm{RR}=1.02(95 \% \mathrm{CI}, 0.99-1.05)$ and

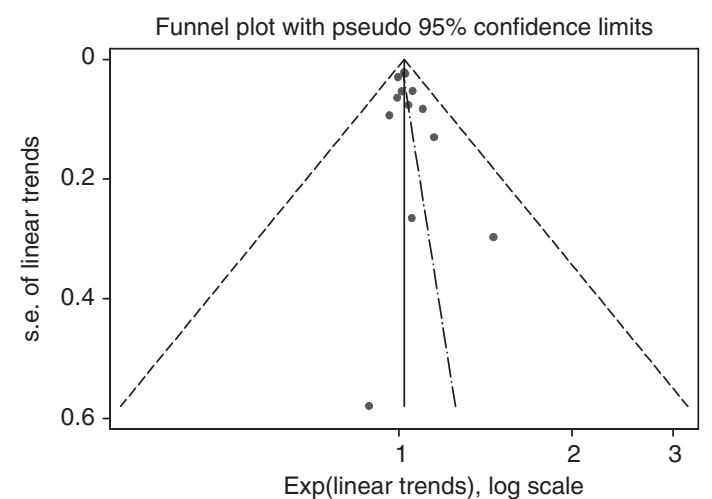

Figure 3 Funnel plot for evaluation of publication bias.

$\mathrm{RR}=1.04(95 \% \mathrm{CI}, 0.95-1.14))$ for every $100 \mathrm{~g}$ per week increment in consumption of red and processed meat, respectively), neither did exclusion of the study that used ovarian cancer mortality as outcome (Sakauchi et al, 2007) $(\mathrm{RR}=1.02$ (95\% CI, 0.99-1.04) and $\mathrm{RR}=1.06$ (95\% CI, 0.98-1.14), respectively). In a further sensitivity analysis of red meat consumption, the summary RR was 1.01 (95\% CI, 0.96-1.06) for studies that adjusted for oral contraceptive use (Larsson and Wolk, 2005; Sakauchi et al, 2007; Schulz et al, 2007; Gilsing et al, 2011), and 1.02 (95\% CI, 0.991.06) for studies that did not (Kushi et al, 1999; Bertone et al, 2002; Kiani et al, 2006; Cross et al, 2007).

Our results are based on risk estimates for total epithelial ovarian cancer. Among the studies included in the meta-analysis, only three examined red and/or processed meat consumption in relation to histological subtype of ovarian cancer (Bertone et al, 2002; Larsson and Wolk, 2005; Schulz et al, 2007). There were no differences in observed associations between the subtypes within those studies.

\section{DISCUSSION}

The results from this meta-analysis of eight prospective studies suggest that red and processed meat consumption is not associated with risk of ovarian cancer. These results are partly in contrast to the conclusions from the previous meta-analysis, including both case-control studies and a smaller number of cohort studies, which reported a positive association with processed meat (Kolahdooz et al, 2010).

A strength of this study, in addition to the use of a doseresponse approach, is that the assessment was based on data from prospective cohort studies only, which are less susceptible to recall and selection bias than retrospective case-control studies. Our findings also have limitations. First, a meta-analysis of observational studies cannot solve inherent problems with confounding in the included studies, which may introduce bias. Although most studies controlled for parity, BMI or waist-to-hip ratio, and total energy intake, other factors suspected to influence the risk of ovarian cancer were less consistently included in the multivariate models. Residual confounding by inadequately measured covariates could also be of concern. Second, our findings are likely to have been affected by misclassification of meat consumption because of imprecise measurement of diet in the included studies. In cohort studies, misclassification is generally non-differential, which most likely attenuates the association. Finally, because studies with null results or small sample sizes tend not to be published, publication bias, which may overestimate the summary $\mathrm{RR}$, could be of concern. However, we found no evidence of publication bias in this meta-analysis. 
Although the dose-response approach to meta-analysis offers advantages over the conventional methodology, it also requires a number of assumptions to be made. In terms of associations between absolute intake levels and disease risk, a meta-analysis can only be as good as the individual study instruments have been. All included studies used FFQs to assess meat consumption, which are generally more valuable to rank study participants according to their consumption than to measure exact levels. In addition, combining results from different studies requires comparing different instruments. Assumptions also had to be made regarding the median level of consumption for each category when this information was missing in the individual studies. However, sensitivity analysis around the assignment of the dose of open-ended top categories did not change the results. Finally, since some studies expressed consumption levels in servings rather than in grams, we had to make assumptions about average serving sizes.

Suggested mechanisms for a potential association between red and processed meat and ovarian cancer include high fat intake, which has been shown to be associated with elevated levels of circulating oestrogens (Hill et al, 1971; Aubertin-Leheudre et al, 2008). Although the role of oestrogen in ovarian cancer aetiology is not yet clear, the current evidence suggests that high levels may promote ovarian carcinogenesis (Lukanova and Kaaks, 2005). In a pooled analysis of 12 cohort studies, a weak positive association was observed for saturated fat intake, whereas other types of fat did not affect the risk of ovarian cancer (Genkinger et al, 2006). An earlier meta-analysis of primarily case-control studies found significant associations for total fat, saturated fat and animal fat (Huncharek and Kupelnick, 2001). Another possible mechanism is that preservation, cooking and/or processing methods can introduce mutagens and carcinogens to meat. These include $\mathrm{N}$ nitroso compounds (NOC), heterocyclic amines and polycyclic aromatic hydrocarbons, many of which have been shown to induce tumours in several animal species and at several sites (Cross and Sinha, 2004). Haeme iron, which is more abundant in red meat than in white meat, has also been shown to stimulate endogenous NOC production (Cross et al, 2003). However, epidemiological studies have linked these compounds primarily to cancers of the gastrointestinal tract (De Stefani et al, 1998; Cross et al, 2010), whereas their potential role in ovarian cancer aetiology has not yet been investigated.

\section{REFERENCES}

Adlercreutz H (1995) Phytoestrogens: epidemiology and a possible role in cancer protection. Environ Health Perspect 103: $103-112$

Aubertin-Leheudre $M$, Gorbach S, Woods M, Dwyer JT, Goldin B, Adlercreutz H (2008) Fat/fiber intakes and sex hormones in healthy premenopausal women in USA. J Steroid Biochem Mol Biol 112: 32-39

Bertone ER, Rosner BA, Hunter DJ, Stampfer MJ, Speizer FE, Colditz GA, Willett WC, Hankinson SE (2002) Dietary fat intake and ovarian cancer in a cohort of US women. Am J Epidemiol 156: 22-31

Chang ET, Lee VS, Canchola AJ, Clarke CA, Purdie DM, Reynolds P, AntonCulver H, Bernstein L, Deapen D, Peel D, Pinder R, Ross RK, Stram DO, West DW, Wright W, Ziogas A, Horn-Ross PL (2007) Diet and risk of ovarian cancer in the California Teachers Study cohort. Am J Epidemiol 165: $802-813$

Cross AJ, Ferrucci LM, Risch A, Graubard BI, Ward MH, Park Y, Hollenbeck AR, Schatzkin A, Sinha R (2010) A large prospective study of meat consumption and colorectal cancer risk: an investigation of potential mechanisms underlying this association. Cancer Res 70: $2406-2414$

Cross AJ, Leitzmann MF, Gail MH, Hollenbeck AR, Schatzkin A, Sinha R (2007) A prospective study of red and processed meat intake in relation to cancer risk. PLoS Med 4: e325

Cross AJ, Pollock JR, Bingham SA (2003) Haem, not protein or inorganic iron, is responsible for endogenous intestinal $\mathrm{N}$-nitrosation arising from red meat. Cancer Res 63: 2358-2360
When investigating meat consumption, it has to be considered that any association with a diet high in meat may in part be attributable to a low intake of fruit and vegetables or other plant foods. Only two of the studies included in this meta-analysis controlled for fruit and vegetable consumption. Fruits and vegetables are high in antioxidants that have been shown to protect cells against oxidative damage and are hypothesised to reduce the risk of cancer (Thompson et al, 1999). In addition, plant foods contain phytoestrogens and fibre that may lower levels of circulating oestrogens (Adlercreutz, 1995; Aubertin-Leheudre et al, 2008). However, few prospective studies have shown significant associations between intake of fruit, vegetables or antioxidants and risk of ovarian cancer, although the overall evidence concerning vegetable consumption indicates a possible inverse association (Koushik et al, 2005, 2006). Another possibility is that a potential association between high meat consumption and risk of ovarian cancer may be mediated through obesity, as a result of high energy intake. Obesity influences endogenous hormones by increasing adrenal secretion of androgens, enhancing conversion of androgens to oestrogens and reducing plasma levels of sex hormonebinding globulin, which results in higher levels of biologically active oestrogen (Siiteri, 1987). In a meta-analysis of 28 studies, a moderate positive association between obesity and risk of ovarian cancer was suggested (Olsen et al, 2007). On the other hand, most of the studies included in our meta-analysis adjusted for BMI or waist-to-hip ratio and for total energy intake.

In conclusion, results from this dose-response meta-analysis suggest that red and processed meat consumption is not associated with risk of ovarian cancer. Considering the borderline significant results, a possible weak association cannot be excluded. However, ovarian cancer risk was only elevated by 2 and $5 \%$ for every $100 \mathrm{~g}$ increment in consumption of red and processed meat, respectively. Although a lower consumption of red and processed meat may offer protection against other types of cancer (Ferguson, 2010), other interventions are needed to reduce the risk of ovarian cancer.

\section{ACKNOWLEDGEMENTS}

This work was supported by research grants from the Swedish Cancer Foundation.
Cross AJ, Sinha R (2004) Meat-related mutagens/carcinogens in the etiology of colorectal cancer. Environ Mol Mutagen 44: 44-55

De Stefani E, Boffetta P, Mendilaharsu M, Carzoglio J, Deneo-Pellegrini H (1998) Dietary nitrosamines, heterocyclic amines, and risk of gastric cancer: a case-control study in Uruguay. Nutr Cancer 30: 158-162

Egger M, Davey Smith G, Schneider M, Minder C (1997) Bias in metaanalysis detected by a simple, graphical test. BMJ 315: 629-634

Ferguson LR (2010) Meat and cancer. Meat Sci 84: 308-313

Ferlay J, Parkin DM, Steliarova-Foucher E (2010) Estimates of cancer incidence and mortality in Europe in 2008. Eur J Cancer 46: 765-781

Genkinger JM, Hunter DJ, Spiegelman D, Anderson KE, Beeson WL, Buring JE, Colditz GA, Fraser GE, Freudenheim JL, Goldbohm RA, Hankinson SE, Koenig KL, Larsson SC, Leitzmann M, McCullough ML, Miller AB, Rodriguez C, Rohan TE, Ross JA, Schatzkin A, Schouten LJ, Smit E, Willett WC, Wolk A, Zeleniuch-Jacquotte A, Zhang SM, SmithWarner SA (2006) A pooled analysis of 12 cohort studies of dietary fat, cholesterol and egg intake and ovarian cancer. Cancer Causes Control 17: $273-285$

Gilsing AM, Weijenberg MP, Goldbohm RA, van den Brandt PA, Schouten LJ (2011) Consumption of dietary fat and meat and risk of ovarian cancer in the Netherlands Cohort Study. Am J Clin Nutr 93: 118-126

Greenland S, Longnecker MP (1992) Methods for trend estimation from summarized dose-response data, with applications to metaanalysis. Am J Epidemiol 135: $1301-1309$ 
Higgins JP, Thompson SG (2002) Quantifying heterogeneity in a metaanalysis. Stat Med 21: $1539-1558$

Hill MJ, Goddard P, Williams RE (1971) Gut bacteria and aetiology of cancer of the breast. Lancet 2: $472-473$

Huncharek M, Kupelnick B (2001) Dietary fat intake and risk of epithelial ovarian cancer: a meta-analysis of 6689 subjects from 8 observational studies. Nutr Cancer 40: $87-91$

Kiani F, Knutsen S, Singh P, Ursin G, Fraser G (2006) Dietary risk factors for ovarian cancer: the Adventist Health Study (United States). Cancer Causes Control 17: 137-146

Knekt P, Steineck G, Järvinen R, Hakulinen T, Aromaa A (1994) Intake of fried meat and risk of cancer: a follow-up study in Finland. Int J Cancer 59: $756-760$

Kolahdooz F, van der Pols JC, Bain CJ, Marks GC, Hughes MC, Whiteman DC, Webb PM (2010) Meat, fish, and ovarian cancer risk: results from 2 Australian case-control studies, a systematic review, and meta-analysis. Am J Clin Nutr 91: 1752-1763

Koushik A, Hunter DJ, Spiegelman D, Anderson KE, Arslan AA, Beeson WL, van den Brandt PA, Buring JE, Cerhan JR, Colditz GA, Fraser GE, Freudenheim JL, Genkinger JM, Goldbohm RA, Hankinson SE, Koenig KL, Larsson SC, Leitzmann M, McCullough ML, Miller AB, Patel A, Rohan TE, Schatzkin A, Smit E, Willett WC, Wolk A, Zhang SM, Smith-Warner SA (2005) Fruits and vegetables and ovarian cancer risk in a pooled analysis of 12 cohort studies. Cancer Epidemiol Biomarkers Prev 14: $2160-2167$

Koushik A, Hunter DJ, Spiegelman D, Anderson KE, Buring JE, Freudenheim JL, Goldbohm RA, Hankinson SE, Larsson SC, Leitzmann M, Marshall JR, McCullough ML, Miller AB, Rodriguez C, Rohan TE, Ross JA, Schatzkin A, Schouten LJ, Willett WC, Wolk A, Zhang SM, Smith-Warner SA (2006) Intake of the major carotenoids and the risk of epithelial ovarian cancer in a pooled analysis of 10 cohort studies. Int J Cancer 119: $2148-2154$

Kushi LH, Mink PJ, Folsom AR, Anderson KE, Zheng W, Lazovich D, Sellers TA (1999) Prospective study of diet and ovarian cancer. Am J Epidemiol 149: 21 - 31

Larsson SC, Wolk A (2005) No association of meat, fish, and egg consumption with ovarian cancer risk. Cancer Epidemiol Biomarkers Prev 14: $1024-1025$

Lukanova A, Kaaks R (2005) Endogenous hormones and ovarian cancer: epidemiology and current hypotheses. Cancer Epidemiol Biomarkers Prev 14: $98-107$

Olsen CM, Green AC, Whiteman DC, Sadeghi S, Kolahdooz F, Webb PM (2007) Obesity and the risk of epithelial ovarian cancer: a systematic review and meta-analysis. Eur J Cancer 43: 690-709
Orsini N, Bellocco R, Greenland S (2006) Generalized least squares for trend estimation of summarized dose-response data. Stata J 6: 40-57

Parkin DM, Bray F, Ferlay J, Pisani P (2005) Global cancer statistics, 2002. CA Cancer J Clin 55: 74-108

Parkin DM, Iscovich J (1997) Risk of cancer in migrants and their descendants in Israel: II. Carcinomas and germ-cell tumours. Int J Cancer 70: $654-660$

Sakauchi F, Khan MM, Mori M, Kubo T, Fujino Y, Suzuki S, Tokudome S, Tamakoshi A (2007) Dietary habits and risk of ovarian cancer death in a large-scale cohort study (JACC study) in Japan. Nutr Cancer 57: $138-145$

Schulz M, Nöthlings U, Allen N, Onland-Moret NC, Agnoli C, Engeset D, Galasso R, Wirfält E, Tjønneland A, Olsen A, Overvad K, Boutron-Ruault MC, Chajes V, Clavel-Chapelon F, Ray J, Hoffmann K, Chang-Claude J, Kaaks R, Trichopoulos D, Georgila C, Zourna P, Palli D, Berrino F, Tumino R, Vineis P, Panico S, Bueno-de-Mesquita HB, Ocké MC, Peeters PH, Lund E, Gram IT, Skeie G, Berglund G, Lundin E, Hallmans G, González CA, Quirós JR, Dorronsoro M, Martínez C, Tormo MJ, Barricarte A, Bingham S, Khaw KT, Key TJ, Jenab M, Rinaldi S, Slimani N, Riboli E (2007) No association of consumption of animal foods with risk of ovarian cancer. Cancer Epidemiol Biomarkers Prev 16: $852-855$

Siiteri PK (1987) Adipose tissue as a source of hormones. Am J Clin Nutr 45: $277-282$

Stroup DF, Berlin JA, Morton SC, Olkin I, Williamson GD, Rennie D, Moher D, Becker BJ, Sipe TA, Thacker SB (2000) Meta-analysis of observational studies in epidemiology: a proposal for reporting. Metaanalysis of observational studies in epidemiology (MOOSE) group. JAMA 283: $2008-2012$

Sueblinvong T, Carney ME (2009) Current understanding of risk factors for ovarian cancer. Curr Treat Options Oncol 10: 67-81

Tavani A, La Vecchia C, Gallus S, Lagiou P, Trichopoulos D, Levi F, Negri E (2000) Red meat intake and cancer risk: a study in Italy. Int J Cancer 86: $425-428$

Thompson HJ, Heimendinger J, Haegele A, Sedlacek SM, Gillette C, O'Neill C, Wolfe P, Conry C (1999) Effect of increased vegetable and fruit consumption on markers of oxidative cellular damage. Carcinogenesis 20: $2261-2266$

Wells GA, Shea B, O'Connell D, Peterson J, Welch V, Losos M, Tugwell P (2011) The Newcastle-Ottawa Scale (NOS) for assessing the quality of nonrandomised studies in meta-analyses. Dept of Epidemiology and Community Medicine, University of Ottawa: Ottawa, Canada, http:// www.ohri.ca/programs/clinical_epidemiology/oxford.asp (accessed 10 February 2011) 